\title{
Genetic diversity of Bradysia difformis (Sciaridae: Diptera) populations reflects movement of an invasive insect between forestry nurseries
}

\author{
B. P. Hurley · B. Slippers · B. D. Wingfield • \\ P. Govender · J. E. Smith $\cdot$ M. J. Wingfield
}

Received: 9 July 2008/Accepted: 23 June 2009

(C) Springer Science+Business Media B.V. 2009

\begin{abstract}
The fungus gnat, Bradysia difformis (Sciaridae: Diptera) has recently been recorded for the first time from South Africa where it has been found in forestry nurseries. The presence of this insect in all the major forestry nurseries as the dominant and only sciarid species raises intriguing questions regarding its origin and population genetic structure. A $395 \mathrm{bp}$ portion of the mitochondrial COI gene was analysed from $B$. difformis individuals collected from four nursery populations in South Africa and three nursery populations in Europe. Shared haplotypes between South African and European populations indicated a historical connection. South African populations showed high genetic diversity and low genetic differentiation. These
\end{abstract}

B. P. Hurley · P. Govender

Department of Zoology and Entomology, University of Pretoria, Pretoria 0002, South Africa

B. Slippers · B. D. Wingfield

Department of Genetics, University of Pretoria,

Pretoria 0002, South Africa

B. P. Hurley $(\bowtie) \cdot$ B. Slippers · B. D. Wingfield ·

M. J. Wingfield

Forestry and Agricultural Biotechnology Institute,

University of Pretoria, Pretoria 0002, South Africa

e-mail: brett.hurley@fabi.up.ac.za

J. E. Smith

Warwick HRI, University of Warwick,

Coventry CV4 7AL, UK patterns most likely reflect multiple and/or relatively large introductions of $B$. difformis into South Africa from its origin combined with subsequent and continued movement of plants between nurseries.

Keywords Bradysia difformis - Mitochondrial sequence diversity $\cdot$ CO-I - Invasive ·

Forestry $\cdot$ Nursery

\section{Introduction}

Bradysia difformis is a Dipteran in the family Sciaridae (fungus gnats). Bradysia difformis has been recorded from many countries in eastern and western Europe, as well as Asia, USA and Brazil (Hellqvist 1994; White et al. 2000; Menzel et al. 2003). The insect was reported in 2000-2001 for the first time in South Africa and occurs in forestry nurseries throughout the country in which it is the only sciarid (Hurley et al. 2007). The recent discovery of $B$. difformis in South Africa represents its first record in the Afrotropical region (H. G. Rudzinski, personal communication). Due to its well-known distribution in Europe (Menzel et al. 2003), B. difformis is believed to have been introduced to South Africa. Eggs or larvae could easily have been accidentally imported on plant material, growth medium or logs. Bradysia difformis is suspected to be involved in transmitting or predisposing pine seedlings to infection by the pitch canker 
fungus, Fusarium circinatum Nirenberg \& O'Donnell in South African nurseries, where the pathogen is one of the most serious impediments to pine production (Viljoen et al. 1994; Wingfield et al. 2008).

This study aimed to evaluate the genetic diversity of $B$. difformis populations in South Africa to shed light on its origin and movement. For this purpose, the sequence diversity of a portion of the mitochondrial COI gene for $B$. difformis populations and from three European populations was determined.

\section{Materials and methods}

Fungus gnats were collected from the four main pinegrowing nurseries in South Africa in January 2005: near Nelspruit and Sabie in the Mpumalanga province, and near Richmond and Hilton in the KwaZulu-Natal province. Adults were collected with yellow plastic sheets $(14.0 \mathrm{~cm} \times 7.5 \mathrm{~cm})$ covered with insect glue (Flytac), which were placed randomly within nurseries, amongst pine seedlings. Adult fungus gnats from nurseries in the UK (in Wellesbourne) and Slovenia (near Ljubljana) were collected with a pooter during June 2001 and October 2004, respectively. Samples were stored in ethanol (70-96\%) until DNA extraction.

DNA was extracted using the PrepMan ${ }^{\mathrm{TM}}$ Ultra Sample Preparation Reagent Protocol (Applied Biosystems), with $100 \mu$ l of PrepMan ${ }^{\text {TM }}$ Ultra Sample Preparation Reagent used per fungus gnat. A portion of the COI gene was amplified by PCR using the primers CI-J-1751 and CI-N-2191 (Simon et al. 1994). PCR reaction mixtures contained final concentrations of: $2 \mu \mathrm{l}$ of DNA extract, $1 \times$ PCR buffer, $0.2 \mathrm{mM}$ of each dNTP, $2.75 \mathrm{mM} \mathrm{MgCl}_{2}, 3.75$ units Taq polymerase (ThermoRed DNA polymeraseSaveen \& Werner AB, Malmö, Sweden), and $0.2 \mathrm{mM}$ of each primer, and were made up with distilled water to reach a volume of $50 \mu \mathrm{l}$. Amplifications were done using a GeneAmp ${ }^{\circledR}$ PCR System 2700 (Applied Biosystems) thermocycler and programmed for an initial denaturation of DNA at $94^{\circ} \mathrm{C}$ for $5 \mathrm{~min}$, followed by 35 cycles of denaturation at $94^{\circ} \mathrm{C}$ for $30 \mathrm{~s}$, annealing at $50^{\circ} \mathrm{C}$ for $30 \mathrm{~s}$ and elongation at $72^{\circ} \mathrm{C}$ for $30 \mathrm{~s}$, and concluding with elongation at $72^{\circ} \mathrm{C}$ for 7 min. PCR products were cleaned using VioGene (Techtum Lab, Umeå, Sweden). Cycle sequence reactions were performed with the ABI PRISM ${ }^{\mathrm{TM}}$ BigDye $^{\text {TM }} 10 \times$ Terminator Cycle Sequencing Ready
Reaction Kit v.2.0 (Applied Biosystems, Foster City, CA), and analysed on a ABI 310 Genetic analyzer (Applied Biosystems).

Raw sequence data were analysed using Seqman software (DNASTAR, Inc.). Both forward and reverse sequences were analysed for all isolates. Alignment files were produced in ClustalX (Thompson et al. 1997). Diversity estimates within localities were calculated using DnaSP v.4 (Rozas et al. 2003). Genetic differentiation was assessed with an analysis of molecular variance (AMOVA) and by calculating pairwise $F_{\mathrm{ST}}$ between populations, using Arlequin v.3.1 (Excoffier et al. 2005). TCS (Clement et al. 2000) was used to produce a network showing the relationship between haplotypes. A BLAST search (Altschul et al. 1997) was done in GenBank to determine the closest sequence match.

\section{Results}

A total of 56 fungus gnats were collected from the four South African nurseries and 31 fungus gnats were used from Europe, representing two populations from Slovenia (8 and 15 individuals) and one population from the United Kingdom (eight individuals). A 395 bp portion of the COI gene was amplified and sequenced revealing 11 polymorphic nucleotide sites representing nine COI haplotypes (Table 1). Haplotype sequences were deposited in GenBank (accession numbers DQ060445 to DQ060500 and EU450767 to EU450797).

Sequence divergence of the nine haplotypes ranged from 0.25 to $1.77 \%$. The greatest sequence divergence was between haplotypes nine and two and between haplotypes nine and seven. These haplotypes are separated by seven mutations each. Haplotype five was present in all the South African and European populations sampled and represented $52 \%$ of the specimens in this study. Besides haplotype five, two other haplotypes (haplotypes two and four) were present in all the South African nursery populations. The European populations were represented by haplotypes two, five and nine; the later was the only haplotype not present in South Africa.

Within-locality genetic diversity was higher in South Africa than in Europe (Table 2). Haplotype diversity for the South African nursery populations ranged from 0.593 to 0.89 and nucleotide diversity 
Table 1 Polymorphic sites of the nine COI haplotypes of $B$. difformis

\begin{tabular}{llllllllllll}
\hline Haplotype & \multicolumn{1}{l}{ Site } & \multicolumn{1}{l}{10} & & & & & & \\
\cline { 2 - 10 } & 6 & 95 & 107 & 135 & 158 & 276 & 364 & 365 & 371 & 374 & 377 \\
\hline H1 & T & A & T & A & A & T & C & A & G & A & C \\
H2 & - & - & - & - & - & - & - & - & A & - & T \\
H3 & - & - & - & - & - & C & - & - & - & - & - \\
H4 & - & - & - & - & - & - & T & - & - & - & - \\
H5 & - & - & - & T & - & - & T & - & - & - & - \\
H6 & - & G & C & - & - & - & - & - & - & - & - \\
H7 & - & G & - & - & - & - & - & - & - & - & - \\
H8 & - & G & - & - & G & - & - & G & - & T & - \\
H9 & C & G & - & - & G & - & - & G & - & T & - \\
\hline
\end{tabular}

Table 2 Diversity estimates of $B$. difformis within localities and of all localities combined

$N$ sample size; $N H$ number of haplotypes; $H$ haplotype diversity; $S$ number of polymorphic sites; $P i$ nucleotide diversity

\begin{tabular}{lrllll}
\hline Locality & $N$ & NH & $H$ & $S$ & Pi \\
\hline Sabie & 15 & 6 & 0.848 & 8 & 0.0056 \\
Hilton & 14 & 7 & 0.890 & 9 & 0.0072 \\
Nelspruit & 14 & 5 & 0.593 & 8 & 0.0032 \\
Richmond & 13 & 4 & 0.744 & 5 & 0.0041 \\
Slovenia_2 & 8 & 2 & 0.536 & 5 & 0.0068 \\
Slovenia_3 & 15 & 3 & 0.362 & 7 & 0.0029 \\
UK & 8 & 1 & 0.000 & 0 & 0.0000 \\
All Europe localties & 31 & 3 & 0.340 & 7 & 0.0036 \\
All SA localities & 56 & 8 & 0.809 & 10 & 0.0050 \\
\hline
\end{tabular}

ranged from 0.0032 to 0.0072 . Haplotype diversity within European nursery populations ranged from 0 to 0.536 and nucleotide diversity ranged from 0 to 0.0068 . The lowest genetic diversity was found in the UK population, which had only one haplotype, but only eight specimens were available from this locality. For the South African populations, genetic diversity was highest for the Hilton population (seven haplotypes), while the lowest genetic diversity was found at Richmond (four haplotypes).

Genetic differentiation $\left(F_{\mathrm{ST}}\right)$ between South African populations was low (Table 3), ranging from -0.00154 to 0.03399 , and none of the populations were significantly different from each other with regards to genetic distance. All variation was within populations, and not between them $\left(F_{\mathrm{ST}}=-0.00093\right.$, $P<0.0001$; AMOVA, Distance method: Pairwise distance). Genetic differentiation was higher between European populations (from 0.0217 to 0.28571 ) than between South African populations, and was significantly different between populations from the two
Slovenia nurseries (Table 3). Genetic differentiation between South African and European populations ranged from -0.00494 to 0.21894 .

\section{Discussion}

The high population diversity is in contrast to expectation for what is believed to be an introduced pest in South Africa and may reflect multiple introductions of $B$. difformis into South Africa. The single most common haplotype (five) was present in all South African and European populations of $B$. difformis. It is expected that the most common haplotypes of the source population would tend to be introduced with a higher probability, meaning that the sampled populations in South Africa and Europe share a source. As more introductions occur, less common haplotypes tend to be sampled in proportionate amounts. The fact that such a population structure is reflected for $B$. difformis in South Africa 
Table 3 Pairwise $F_{\mathrm{ST}}$ estimates between populations of $B$. difformis, based on COI sequence data

\begin{tabular}{|c|c|c|c|c|c|c|c|c|}
\hline & & \multicolumn{4}{|c|}{ South Africa } & \multicolumn{3}{|l|}{ Europe } \\
\hline & & Sabie & Hilton & Nelspruit & Richmond & Slovenia_1 & Slovenia_2 & UK \\
\hline \multirow[t]{4}{*}{ South Africa } & Sabie & 0 & & & & & & \\
\hline & Hilton & -0.01789 & 0 & & & & & \\
\hline & Nelspruit & 0.01566 & -0.00154 & 0 & & & & \\
\hline & Richmond & -0.03208 & 0.03399 & -0.00314 & 0 & & & \\
\hline \multirow[t]{3}{*}{ Europe } & Slovenia_1 & $0.14177 *$ & 0.02323 & $0.17465^{*}$ & $0.21894 *$ & 0 & & \\
\hline & Slovenia_2 & 0.02547 & 0.02674 & -0.0394 & -0.00494 & $0.17394 *$ & 0 & \\
\hline & UK & $0.10491 *$ & 0.07616 & -0.03081 & 0.06806 & 0.28571 & -0.0217 & 0 \\
\hline
\end{tabular}

* Statistically different at the 0.05 level

supports the hypothesis of multiple and/or large introductions.

An important result of this study was evidence of close genetic similarity between populations of B. difformis in four different nurseries in South Africa, despite the fact that some are distant from each other. This includes the co-occurrence of low frequency haplotypes in distant populations. This result suggests frequent movement of $B$. difformis between nurseries in South Africa.

The substantial distances between some South African nurseries sampled and reports of sciarids as weak fliers (Hungerford 1916) make it unlikely that $B$. difformis could have migrated naturally between them. It is more likely that genetic material was moved by humans between populations; pine nursery plants and bark medium are moved between forest nurseries in South Africa. Although this movement is not frequent, it appears to suffice to ensure the low observed genetic differentiation between the populations.

Acknowledgments We thank the members of the Tree Protection Cooperative Programme (TPCP), for their assistance in this study. We also thank the Department of Forest Mycology and Pathology, Swedish University of Agricultural Sciences, Uppsala, Sweden, for the use of their facilities and Dr. Lea Milevoj (University of Ljubljana) for providing specimens from Slovenia. The National Research Foundation (NRF), members of the TPCP and the THRIP initiative of the Department of Trade and Industry (DTI), South Africa are recognised for financial support.

\section{References}

Altschul SF, Madden TL, Schäffer AA, Zhang J, Zhang Z, Miller W, Lipman DJ (1997) Gapped BLAST and PSI-
BLAST: a new generation of protein database search programs. Nucleic Acids Res 25:3389-3402. doi:10.1093/ nar/25.17.3389

Clement M, Posada D, Crandall KA (2000) TCS: a computer program to estimate gene genealogies. Mol Ecol 9:16571660. doi:10.1046/j.1365-294x.2000.01020.x

Excoffier L, Laval LG, Schneider S (2005) Arlequin ver 3.0: an integrated software package for population genetics data analysis. Evol Bioinform Online 1:47-50

Hellqvist S (1994) Biology of Synacra sp. (Hym., Diapriidae), a parasitoid of Bradysia paupera (Dipt., Sciaridae) in Swedish greenhouses. J Appl Entomol 117:491-497

Hungerford HB (1916) Sciara maggots injurious to potted plants. J Econ Entomol 9:538-553

Hurley BP, Govender P, Coutinho TA, Wingfield BD, Wingfield MJ (2007) Fungus gnats and other Diptera in South African forestry nurseries and their possible association with the pitch canker fungus. S Afr J Sci 103:43-46

Menzel F, Smith JE, Colauto NB (2003) Bradysia difformis Frey and Bradysia ocellaris (Comstock): two additional neotropical species of black fungus gnats (Diptera: Sciaridae) of economic importance: a redescription and review. Ann Entomol Soc Am 96:448-457. doi:10.1603/ 0013-8746(2003)096[0448:BDFABO]2.0.CO;2

Rozas J, Sanchez-DelBarrio JC, Messeguer X, Rozas R (2003) DnaSP, DNA polymorphism analysis by the coalescent and other methods. Bioinformatics 19:2496-2497. doi:10.1093/bioinformatics/btg359

Simon C, Frati F, Beckenbach A, Crespi B, Liu H, Flook P (1994) Evolution, weighting, and phylogenetic utility of mitochondrial gene sequences and a compilation of conserved polymerase chain reaction primers. Ann Entomol Soc Am 87:651-701

Thompson JD, Gibson TJ, Plewniak F, Jeanmougin F, Higgins DG (1997) The ClustalX windows interface: flexible strategies for multiple sequence alignment aided by quality analysis tools. Nucleic Acids Res 24:4876-4882. doi:10.1093/nar/25.24.4876

Viljoen A, Wingfield MJ, Marasas WFO (1994) First report of Fusarium subglutinans f. sp. pini on pine seedlings in South Africa. Plant Dis 78:309-312 
White PF, Smith JE, Menzel F (2000) Distribution of Sciaridae (Dipt.) species infesting commercial mushroom farms in Britain. Entomologists Mon Mag 136:207-209

Wingfield MJ, Hammerbacher A, Ganley RJ, Steenkamp ET, Gordon TR, Wingfield BD, Coutinho TA (2008) Pitch canker caused by Fusarium circinatum - a growing threat to pine plantations and forests worldwide. Plant Pathol 51:397. doi:10.1046/j.1365-3059.2002.00710.x 